\title{
Project Beeswax: On the Problem of Beehive Location for Optimum Pollination
}

\author{
Abdel Salhi' ${ }^{1 *}$ andAndrew Lewis ${ }^{2}$ \\ ${ }^{1}$ Department of Mathematical Sciences, University of Essex, UK \\ ${ }^{2}$ Simulsys Ltd, Chelmsford, UK
}

Submission: February15, 2018; Published: August 24, 2018

*Corresponding author: Abdel Salhi, Department of Mathematical Sciences, University of Essex, UK; Email: as@essex.ac.uk / andy.lewis01@gmail.com

Keywords: Food production; Pollination; Fruit; Trees; Honeybees; Crop yield

\section{Introduction}

Food production is to a large extent dependent on pollination. However, pollinators such as honeybees, bumblebees, solitary bees, hover flies, butterflies and other wild pollinators are being lost at an alarming rate due to loss of habitat, disease [1], and excessive use of pesticides and in particular neonicotinoids. Indeed, a recent report by the European Food Safety Agency concluded that some pesticides posed a high risk to pollinators such as honeybees [2]. As a result, honeybees are becoming an increasingly scarce resource. An effective use of this resource is therefore in order. This report describes an optimization approach to deploying honeybees in an effective way for pollinating fruit trees and other flowering plants.

Pollination with honeybees to boost crop yield is not new. Current practice consists in beehives arriving on trailers and left on them on the edge of the fields where the plants to pollinate sit.This approach is of course convenient since the beehives are all kept together, and the trailers are simply stowed away at the end of the hire period. But, pollination is not well distributed, leaving distant parts of the fields uncovered. The number of needed beehives may well be overestimated too, which will impact negatively on pollination elsewhere, since there are not enough bees to go around.It is, therefore, necessary to look at this decision-making problem from a systematic viewpoint, so that appropriate (possibly optimal) positions for the beehives can be found and only the necessary number of beehives are used.The approach expanded here advocates the placement of beehives among the trees and plants where they are needed.Their number and locations are defined based on the area of the field, the number of plants to pollinate and the distance a bee will cover to forage.

\section{The Beehive Location Problem}

We refer to this problem as the Beehive Location Problem (BLP) which is that of placing the least number of beehives to pollinate a given number of trees. An alternative definition may describe it as the problem of placing strategically any available beehives for most effective pollination. This latter definition is not equivalent to the former.It requires an extra constraint on the number of available beehives. The problem can be complicated if one acknowledges that no two orchards are identical. In places the trees may be old and large, and in others they may be small and densely planted as in the modern concept orchards. Some may have obstacles that will hamper a regular distribution of the beehives. Others may have neighboring fields covered in flowering plants too, which will attract the bees. It is also important to take into account the risks of deploying bees in the vicinity of urban areas.Bees themselves may behave differently depending on their type, the size of their colony and so on.Looking at the problem in its most general form, taking into account all aspects including the weather, makes it highly intractable even for modest size instances.

\section{The Optimization Model}

Suppose that the trees to pollinate are randomly located in a flat polygon-shaped field. Assume that the bee colonies are of the same size and that any tree within foraging distance of the bees in a hive will be pollinated. Every hive used has a cost. We want to pollinate all trees at minimum cost.In this form, BLP is the Set Covering Problem (SCP) [3,4], which is the problem of covering a subset of objects from a larger set N with other subsets $B_{j}$ of N at minimum cost since each subset $B_{j}$ has cost $c_{j}$. Note that SCP is NP-Hard [5].

As an SCP, we need to define the subsets of beehive locations with which we would like to cover all the trees. Assume that a bee may visit any tree within a circle of radius $R$. Then, given a tree at the foot of which we place a beehive, all trees within radius $R$ of this tree/beehive, do not need any further bees for pollination. 
It is, therefore, necessary to find all trees within distance $R$ of each tree.For this we need the distances separating trees and an assumed value for $R$.

Let there be n trees numbered from $i=1$ to $n$. Let $B_{j}$ be the set of all trees within distance $R$ of tree $\mathrm{T}_{\mathrm{j}}$. There are $\mathrm{n}$ such sets $B_{j}, j=1, \ldots, n$. Let D be the matrix of distances $d_{i j}$ between trees $i$ and $j$, with $i \neq j$ and $d_{i i}=0$.

$$
D=(d i j, i=1, . ., n, j=1, . ., n) .
$$

It is possible to find all sets $B_{j}, j=1, \ldots, n$. From these subsets, it is also possible to find a $(0,1)$-matrix which indicates to which subset(s) $B_{j}$ a given tree $i$ belongs;

$$
A=\left(a_{i j}, i=1, . ., n, j=1, . ., n\right)
$$

where

$$
a_{i j}=1
$$

if tree $i$ is in subset $B_{j}$ and 0 otherwise.

Define

$x_{j}=\left\{\begin{array}{l}1 \text { if } B j \text { is in the cover, i.e. if we place abeehive at the foot of tree } \\ 0 \text { Otherwise }\end{array}\right.$

Then, the optimisation model is as follows.
I. $\quad \sum_{j=1}^{n} c_{j} x_{j}$

II. Subject to $\sum_{j}^{n} a_{i j} x_{j} \geq 1$, for $i=1, \ldots, n$

III. $\quad x_{j} \in\{0,1\}, j=1, \ldots, n$

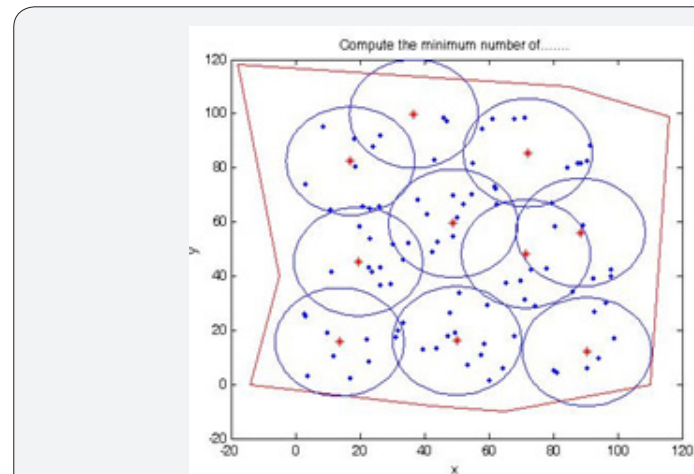

Figure 1: Minimum cover of 100 trees with 9 beehives (in red).

where line 1 is the objective function, line 2 is the constraints saying that every tree $i$ must be covered by at least one beehive and line 3 saying that the decision variables are binary. Note that other constraints can be added to this model if necessary. An instance of the problem with 100 trees randomly generated in a $100 \times 100 \mathrm{~m}^{2}$ grid, and a foraging distance of 20 metres was solved in Matlab using bintprog. The results are represented in Figure 1. Results on an application of the model to real data are represented in Figure 2.

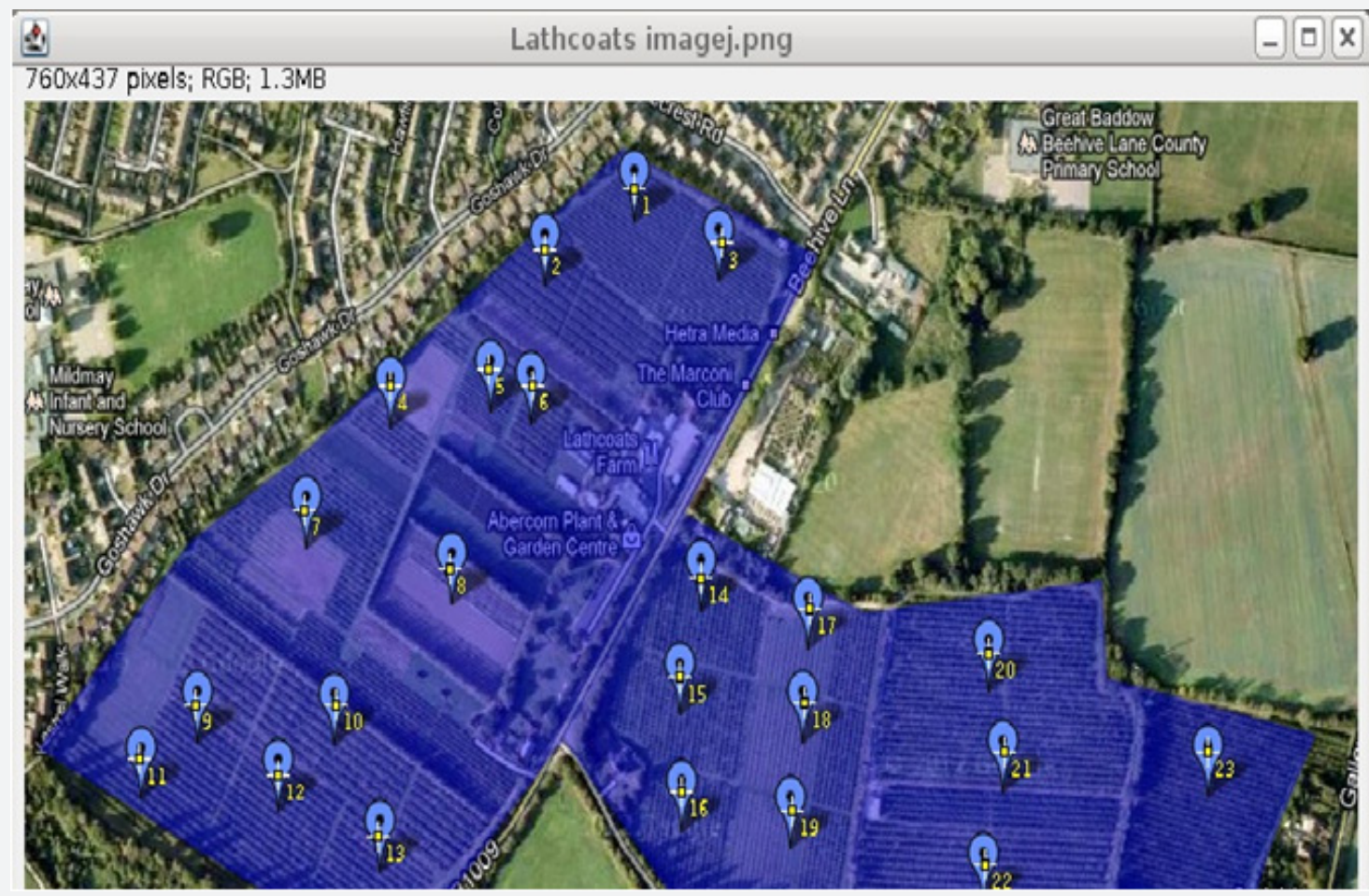

Figure 2: Practical application on a farm in Chelmsford, Essex, UK. 


\section{Conclusion}

Honeybees are essential for our food security. Yet, they are becoming scarce for many reasons. While it is important to save them, it is also important to use them efficiently to improve crop yield. We have introduced the Beehive Location Problem and solved it as a Set Covering Problem. Although the problem is NP-Hard, practical instances can be solved to optimality in reasonable times. An important aspect of BLP is the many parameters that have to be taken into account such as obstacles on the ground when placing the beehives, logistics fuel costs etc... A more comprehensive model is therefore worth building and investigating.

\section{References}

1. Varroa destructor Anderson and Trueman (Arachnida: Acari: Varroidae)

2. Mark Kinver (2013) Bee deaths: EU delays action on pesticides ban

3. Nemhauser G, Wolsey L (1988) Integer and Combinatorial Optimization, Wiley Interscience, USA: 784.

4. Salhi A (2012) Combinatorial Optimisation, MA306 Lecture Notes.

5. Garey MR, Johnson DS (1990) A guide to the theory of NP-Completeness, W.H.Freeman, NY

\section{Your next submission with Juniper Publishers will reach you the below assets}

- Quality Editorial service

- Swift Peer Review

- Reprints availability

- E-prints Service

- Manuscript Podcast for convenient understanding

- Global attainment for your research

- Manuscript accessibility in different formats ( Pdf, E-pub, Full Text, Audio)

- Unceasing customer service

Track the below URL for one-step submission https://juniperpublishers.com/online-submission.php 
